\title{
Considerations for Machine Harvesting Fresh-market Eastem Thomless Blackberries: Trellis Design, Cane Training \\ Systems, and Mechanical Harvester Developments
}

Fumiomi Takeda ${ }^{1}$ and D onald L. Peterson ${ }^{2}$

Additional INDEX wORDS. R ubus, brambles, engineering, floricanes, fruit, management, primocanes, quality

Summary. There is increased interest in growing blackberries in the $U$ nited States for the fresh fruit market. For fresh market blackberry production, $>350 \mathrm{~h} /$ acre $\left(900 \mathrm{~h} \cdot \mathrm{ha}^{-1}\right)$ of work is required to hand pick blackberries over a season that lasts 5 weeks with harvest every 2 days. Existing bramble mechanical harvesters can detach fruit from plants trained on a vertically oriented I trellis and harvest more cheaply than when harvested by hand, but the harvested fruit does not have fresh-market quality. We developed a cane training and trellis system for semierect blackberries to orient canes horizontally with the fruit positioned below the canes. Also, we developed an over-the-row mechanical harvester that uses vibrating nylon rods on a drum to shake fruit from horizontally trained canes onto a moving fruit-catching surface directly under the canopy to minimize impact damage to fruit. A new trellis design, new cane training practices, and new harvesting technologies have allowed fruit to be removed efficiently and be acceptable for fresh-market sales. This production system has been evaluated economically and appears to be profitable. It could overcome the high cost of handpicking, which has limited the expansion of fresh-market blackberries.

$\mathrm{n}$ the last 30 years, the U.S. D epartment of Agriculture (U SD A) has released seven semierect, genetically thornless blackberry cultivars: 'Black Satin', 'Smoothstem', 'T hornfree', 'D irksen Thornless', 'H ull Thornless', 'Chester Thornless', and 'T riple Crown'. These cultivars are characterized by vigorous, semierect, smooth canes, and high productivity (M oore and Skirvin, 1990). The latter two have large, firm fruit, improved fresh-market and processing qualities ( $\mathrm{H}$ alat et al., 1997), and are now commercially grown in states along the midAtlantic coast, in the M idwest, and along the Pacific coast.

The expansion of blackberry production into colder areas has been limited because of a lack of cold hardiness in existing cultivars (Warmund et al., 1992). These blackberries are produced mainly on small-acreage farms and hand picked for fresh-pack and pick-your-own markets.

USDA-ARS, Appalachian Fruit Research Station, 45 Wiltshire Road, Kearneysville, WV 25430.

The cost of publishing this paper was defrayed in part by the payment of page charges. U nder postal regulations, this paper therefore must be hereby marked advertisement solely to indicate this fact. 
Typically, theripefruit of semierect blackberries are harvested over a 5- to 6-week period at 2- to 4-d intervals and can require as much as $350 \mathrm{~h} /$ acre $\left(900 \mathrm{~h} \cdot \mathrm{ha}^{-1}\right)$ of work if hand harvested (Brown et al., 1983). Scarcity of workers and the high cost of harvest labor have prevented increased commercialization of semierect blackberries. The L incoln canopy system (D unn et al., 1976), Gjerde method (O ydvin, 1986), slanted trellises (Peterson et al., 1992; T akeda and Peterson, 1996), and the variations of the shift trellis (Stiles, 1995) have positioned the fruiting zone of raspberries and blackberries to enable the fruit to be picked faster and to facilitate mechanical harvest operation.

M echanical harvesters have been developed to rapidly harvest large acreage of blackberries for processing ( $M$ artin and $L$ awrence, 1976). M achine-harvested blackberries are higher-quality fruit (larger fruit, higher percentage of total soluble solids, lower acidity, and superior color) than hand picked fruit (M orris et al., 1978). H owever, no blackberries have been machine harvested for freshmarket use (M oore and Skirvin, 1990), and harvesting by machine has been shown to reduce the amount of sal eable fruit compared with hand picking (Kingston, 1991).

This paper presents research conducted at the Appalachian Fruit Research Station, Kearneysville, W.Va., to develop alternative cane-training practices, trellis designs, and a new mechanical harvesting concept for the semierect, eastern thornless blackberry cultivars. They could ultimately allow cheaper, highly mechanized operationsto harvest freshmarket-quality fruit.

\section{Training and pruning for machine harvesting}

Semierect blackberries are planted typically in rows spaced 10 to $12 \mathrm{ft}$ ( 3 to $3.6 \mathrm{~m}$ ) apart with plants set at 5 to $8 \mathrm{ft}$ ( 1.5 to $2.4 \mathrm{~m}$ ) apart in the row and maintained in a hill culture system. The plants have a semierect growth habit and must be supported by a trellis post-and-wire system. As the primocanes grow, lateral canes develop at the axils of leaves. To promote the growth of these lateral canes along the entirelength of the cane, primocanes are tipped as they extend beyond the top trellis wire. The laterals that emerge at the base of primocanesaregenerally large and stiff and not amenable for hand manipulation. $\mathrm{H}$ owever, the few suckers that radiate from the crown parallel with the row direction may be left and trained to trellis wires for fruit production.

A successful machine-harvesting system must include a trellis design to shape the plant into a narrow, unobstructed fruiting canopy. Thisallows the shaking mechanism to be positioned into the plant and the fruitcatching surface to be placed just below the fruiting canopy where fruit will be damaged least. The common support system for eastern thornless blackberries has been the standard I system ( Fig. 1a) consisting of post or stake $\approx 6.5$ $\mathrm{ft}(2-\mathrm{m})$ tall with two or more wires spaced evenly on the post. During the summer, as many assix strong primocanes are tied to these wires and tipped just above the top wire to promote lateral cane development. Additionally, all laterals originating near the ground and weak primocanes are removed. Following harvest, old floricanesaretypically cut off at ground level. In the winter, the laterals in the fruiting zoneare pruned to 20 inches $(0.5 \mathrm{~m})$ in length (Steiner et al., 1983).

Although the standard I system is relatively cheap, our early work indicated that the lateral canes were damaged considerably and fruit were bruised excessively during the harvest-and-catch operation (Takeda et al., 1989). Since the lateral caneswerenot tied to the trellis wires, the energy transmitted from the harvester rod action to individual fruit was not sufficient to detach many berries. Also, we observed that lateral cane and fruiting lateral numbers were low in the middle portion of the trellis because there was insufficient light for axillary bud development.

\section{Trellis designs}

At the A ppalachian Fruit Research Station, we evaluated several trellis designs that expanded the canopy surfaceto increase yield and makethefruit moreaccessiblefor picking (Takeda et al., 1989). In all of the trellis
Fig. 1. Experimental blackberry trellis systems: (a) I, (b) V, (c) $T$, (d) $Y$, and (e) rotatable cross-arm $Y$.

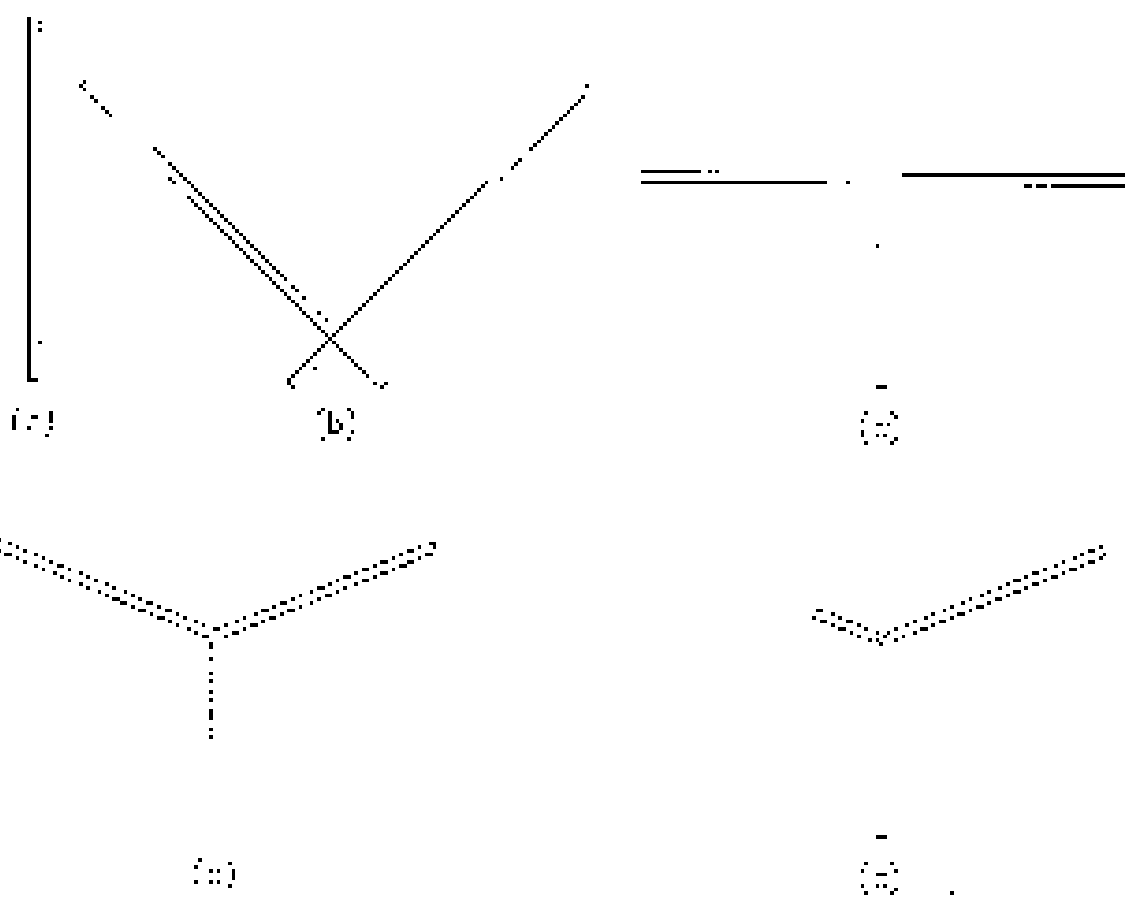


Fig. 2. Schematic of rotatable cross-arm Y trellis. systemsevaluated, supports were constructed with standard 1.5-inch (38-mm) welded black pipes for better stability. Galvanized hightensile wire (12.5 gauge) was used in all the trellis systems. 0 ther points considered in these trellis designs were the cost of materials and fabrication, cropping efficiency, and whether they would be compatible with cultural methods used and could be harvested mechanically. In the last ten years, modified trellis support designs such as $\mathrm{T}, \mathrm{V}, \mathrm{Y}$, and modified $Y$ with a rotatable cross-arm (RCA) have been investigated (Figs. 1 and 2). The details of fabrication and installation techniques for these trellis systems are discussed by Peterson et al. (1992) and Takeda and Peterson (1996).

\section{Cane training and pruning techniques}

All the trellis systems, except the I trellis, allowed the floricanes and primocanes to be separated into two canopies. To do this, canes needed to be trained weekly throughout the summer oncethey werehigh and strong enough to be pulled or bent. In the $\mathrm{V}$ trellis, primocanes were tied to the bottom wire on the side of trellis not occupied by floricanes. U p to five primocanes per hill were trained on the wire. When they grew 8 inches $(20 \mathrm{~cm})$ beyond the top wire, they were pruned back to the top wire. In late summer, the hanging lateral canes were mechanically hedged to prevent them from tip layering. Small primocanes that emerged later in the season were usually removed at ground level. In the winter, selected lateral canes, oriented along the row, were shortened to 15 nodes and tied to trellis wire. All other lateral canes were removed.

In the $T$ and $Y$ trellises, primocanes were trained up to a wire at the top of post. The primocane tips were then bent so that the subsequent growth would be horizontal ei- ther along the wire or perpendicular to it. $\mathrm{On}$ plants where the primocanes were bent parallel to the wire, the canes were tipped when they reached the next plant. The lateral canes that developed on the horizontal portion of the primocanes were pulled down and tied to wires on the cross arm not occupied by floricanes. Lateral canes that could not be tied to the trellis were removed. O $\mathrm{n}$ plants where the primocanes were trained to grow perpendicular to the row and to the side not occupied by floricanes, the shootsweretipped as they grew beyond the outermost wire to promote lateral cane growth. After harvest these lateral canes were pruned back to $\approx 15$ nodes and tied to wire on the cross arm.

The permanent, wide cross-arms of the $\mathrm{T}$ and $\mathrm{Y}$ trellises made many primocanes inaccessible. So to make them more accessible, the R CA Y trellis system was developed. In the RCA Y system, primocanes $>40$ inches $(1 \mathrm{~m})$ tall were tied to the training wire on the center post and bent to grow horizontally to the next plant where they were tipped. The lateral shoots on the horizontal portion of primocanes grew mostly upward and were confined between the main trellis cross arm and short stationary arm (Fig. 3a). Lateral canes that grew downward and could not be repositioned over the wires were pruned.

In the fall, the main trellis cross-arm was swung over to the side with the short stationary arm (Fig. 3b). The lateral canes were then tied to thetop or outermost wireon themain trellis cross arm and trimmed back. During this period, ties that held the lateral portion of primocanes to the training wire were removed. The cross-arm was left in this position or $\approx 22.5$ degrees above the horizontal. In late spring when most of the primary flowers had opened (Fig. 3c), the cross-arm was again swung back to the other side for harvest operation (Fig. $3 d)$. When most of the secondary flowers had bloomed, a crew of three workers rotated the entire row of trellis cross-arms with the lateral canes attached to the outer wire by rotating each cross-arm 135 degrees about the pivot point at the top of post to the other side of the post. Therotation of trelliscrossarms resulted in the fruiting laterals that were previously upright to hang from the lateral canes. Therotation of crossarms occurred without any loss of floricanesorfruiting laterals. The leaves on the fruiting laterals reoriented themselves within 2 weeks. After harvest the floricanes were removed from the main cross-arm.

The angle at which the 


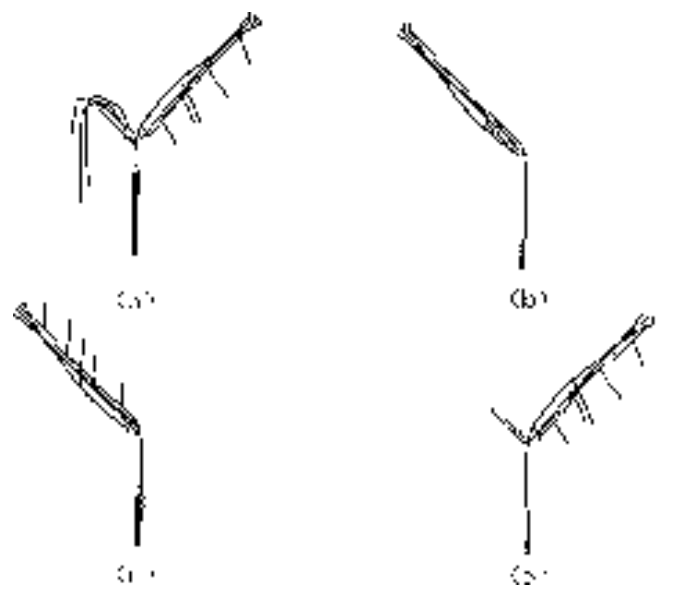

Fig. 3. R otatable cross-arm $Y$ trellis (a) in July with the rotatable cross-arm for machine harvest and the short, stationary arm catching lateral canes, (b) after harvest, with the cross-arm rotated for lateral cane tying, (c) at peak bloom in early J une, showing the orientation of flower clusters, and (d) postbloom with the cross-arm now pivoted to the other side of trellis post for harvest. $N$ ote that now the fruiting laterals are positioned below the canopy.

cross-arm was positioned during the period from budbreak to full bloom affected the distribution of flowering shoots on thetrellis. The relationship between the orientation of lateral canes achieved with the cross-arm of $Y$ trellis system set at different angles and the amount of flowering shoots that developed above the cross-arms is shown in Fig. 4. In summary, the resultsindicated that the closer the trellis cross-arm was held parallel to the ground the greater the proportion of flowering shoots that emerged above the cross arm. 0 rientation of lateral canes to $<30$ degrees above the horizontal during the period following budbreak until an onset of bloom maximized the numbers of fruiting laterals developing above the trellis cross-arms (Fig $3 c$ ). The rotation of the cross-arms to the harvest position placed these fruiting laterals now under the canopy (Fig. $3 \mathrm{~d}$ ). The distribution of flowering shoots in a vertically oriented trelliswas $\approx 55 \%$ and $45 \%$, with greater numbers of flowering shoots emerging to the east side of a north-south oriented row (Fig. $4)$.

\section{Advantages and disadvantages of trellis systems}

The $V$ trellis provided a narrow, unobstructed hedge-likestructure and separation of floricanes and primocanes. The angle between the two posts was set sufficiently wide to allow the shaking heads of the U SD A experimental brambleharvester insidetheV to shakethefruit from the top and detach fruit onto a catching surface located to the outside and below the fruiting canopy. The $V$ trellis had a span between thetwo postsat their apex of $\approx 10 \mathrm{ft}(3 \mathrm{~m})$ and required a row spacing of at least $22 \mathrm{ft}(6.5$ $\mathrm{m})$, which makes it impractical for commercial blackberry operation.

In the $T$ and $Y$ trellis systems, the shaking mechanism could be positioned above the fruiting canopy and the fruit-catching surface just below the canopy. The distance the fruit fell was rather short, thus minimizing fruit damage. $\mathrm{H}$ owever, there were some disadvantages to these two trellises. Fruiting laterals developed upward above the tied canes and fruit were exposed to the sun, resulting in higher incidences of sun scorched fruit. Field observations indicated that insects, such as the J apanese beetle, preferred feeding on fruit on the upper canopy surface than in the canopy interior or lower canopy surface (unpublished data). Also, direct contacts on the fruiting laterals by the shaking rods caused more breakage of fruit clusters and severely bruised some fruit.

The RCA trellis system simplified the primocane training procedure and reduced labor required for summer cane training ( $\mathrm{H}$ arper et al., 1998). In this system, which permitted the reo rientation of the established canopy, the fruiting laterals could beoriented downward below the trellis cross-arm. The fruit was thus shaded by the foliage and exposure to direct sunlight was decreased. During machine harvest, the shaking rods mainly vibrated the lattice of lateral canes on the trellis wires and direct impact of the fruit was minimized. The harvester's catching surface could be positioned directly underneath the fruit clusters, minimizing the distance the detached fruit fell. Another advantage of this system is that rows could be established using the conventional, commercial row spacing of
Fig. 4. Relationship between the angle of cross-arm for training lateral canes and percentage of flowering shoots developing upward above the tied canes.

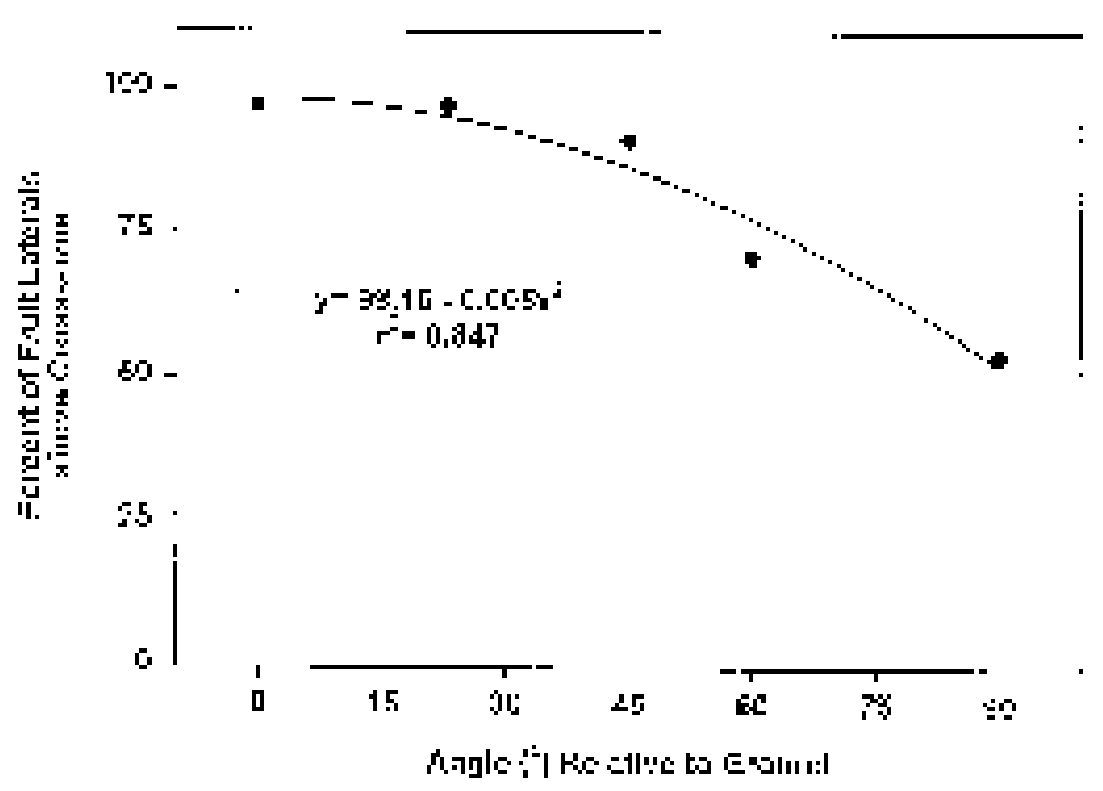




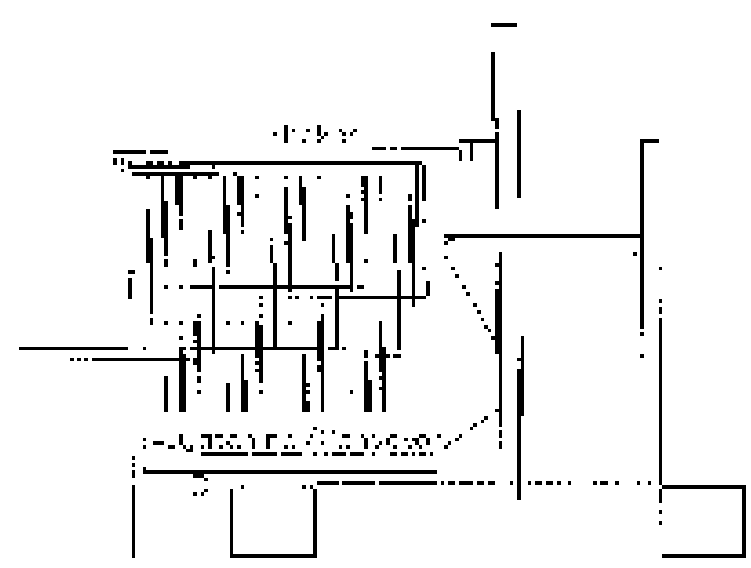

:4:

Fig. 5. Schematic of trailer-mounted U SD A blackberry harvester showing (a) front view and (b) side view.

$11 \mathrm{ft}(3.3 \mathrm{~m})$. I t al so has theflexibility of permitting an efficient hand harvest of fruit when the cross-arm is positioned at 60 degreesfrom the horizontal. In contrast, other trellis systems evaluated for split canopy development and machine harvestability required much wider, commercially unacceptable row spacings. The major disadvantage of this system was the significantly higher cost of fabricating the rotatable cross-arm system.

\section{Machine harvesting developments}

T raditional mechanical blackberry harvesters use three types of shaking mechanisms. The first consists of one or more pairs of oscillating horizontal beater bars that provide a slapping action to remove the fruit (Booster et al., 1983). The second uses a spiked drum that is oscillating in horizontal plane relative to the rotation of the drum, activated by either an inertia drive (Weygandt, Inc., C anby, O re.) or an eccentric cam mechanism (Blueberry Equipment, Inc., South $\mathrm{H}$ aven, $M$ ich.). The third uses a spiked drum that is oscillated vertically (Korvan, I nc., L ynden, Wash., and Littau, Inc., Stayton, O re.).

In 1988, we began blackberry harvest mechanization research. A prototypeharvester with positive-displacement spike drumsimparted nearly uniform displacement and acceleration within thefruiting canopy (Peterson et al., 1989, 1992). I was relatively simple in design and initially all harvesting components were mounted on a twowheeled trailer that could be towed by a tractor (Fig. 5).

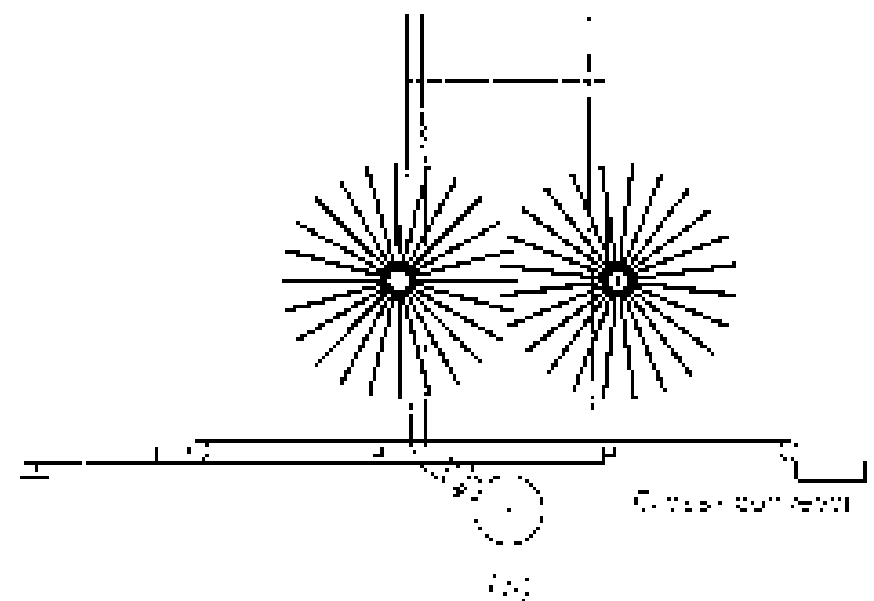

This trailer-mounted prototype harvester was used to harvest ' $C$ hester Thornless', 'H ull Thornless', and 'T hornfree' blackberries trained to $T$, $V$, and $Y$ trellis systems every $2 d$ throughout the harvest season in 1990, 1991, and 1992 (Peterson et al., 1992). Very few fruit fell to the ground because, in thesetrellis systems, the fruiting laterals were located away from the plant crown. Fruit removal from $\mathrm{V}$ trellis was acceptable. M ore than $90 \%$ of ripe fruit was detached while limiting the detachment of immature fruit to $<10 \%$ of the total harvested. In the $T$ and $Y$ trellises the harvester removed $85 \%$ and $88 \%$ of the ripe fruit, respectively.

$\mathrm{H}$ arvested fruit was acceptable for processing, with total soluble solids of $9.1 \%$, titratableacids of $0.8 \%$, and $\mathrm{apH}$ of 3.5 ( $\mathrm{H}$ alat et al., 1997). Alternateday harvest schedules minimized the amount of overripe fruit. These early field tests indicated that 'Chester Thornless' fruit were firm enough to be harvested mechanically and retain their fresh-market quality. ' $\mathrm{H}$ ull Thornless' and 'Thornfree' fruit were too soft. F ruit on canes hanging below the trellis or on long fruiting laterals could not beshaken vigorously enough to be detached. Fruit from the $T$ and $Y$ trellises had better quality as they had shorter distances to fall to the catching surface than those from the $V$ trellis.

In 1995, 'C hester Thornless' blackberries trained to $\mathrm{T}$ and $\mathrm{Y}$ trellises were machine harvested on alternate days. The harvesting machine had a cushioned, horizontal conveyor installed to catch the fruit. The conveyor carried fruit to the rear of the harvester where it was transferred laterally by another conveyor belt into containers. $\mathrm{H}$ and sorting of fresh-market-quality fruit was done on the cross conveyor belt. As much as $70 \%$ of the machine detached fruit was fresh-market quality. Q uality evaluations of fresh-market-quality fruit stored for $7 \mathrm{~d}$ at $45^{\circ} \mathrm{F}$ $\left(7^{\circ} \mathrm{C}\right)$ indicated that the fruits werefree of molds and still relatively firm. Juice did not leak from the fruit. The results suggested that the U SD A experimental blackberry harvester can effectively machine harvest thornless blackberry cultivars such as 'Chester Thornless' with fresh-market quality.

In 1997, a new harvester, designed specifically to machine harvest blackberries on the RCA trellis system, was field tested (Fig. 6). Theinsidetunnel of the harvester was $9 \mathrm{ft}$ wide $\times 10 \mathrm{ft}$ high (2.7 $\mathrm{m}$ wide $\times 3.0 \mathrm{~m} \mathrm{high}$ ) and the overall width of the machinewas $13.7 \mathrm{ft}$ (4.1 m). A single spiked-drum shaker was installed inside the tunnel. The $4 \mathrm{ft}$ $\times 8$-ft $(1.2 \times 2.4-\mathrm{m})$ cushioned and moving catching surface was located under the shaker unit and inclined 18 degrees from the horizontal. The moving catching surface conveyed the fruit to a transfer conveyor on one side of the harvester where leaves and trash were separated and immature, bruised, and overripe fruit were hand sorted. Freshmarket-quality fruit dropped into halfpint $(0.25-\mathrm{L})$ plastic tills.

'Chester Thornless' blackberries on the RCA trellis system were machine harvested every other day throughout the harvest season with the prototype over-the-row harvester. The harvester was operated at 5 to 6 $\mathrm{Hz}$ with maximum displacement at the tips of the rods set at 7 inches ( 175 $\mathrm{mm})$ and at a $0.6-\mathrm{mph}\left(1 \mathrm{~km} \cdot \mathrm{h}^{-1}\right)$ ground speed. The spike-drum shaker was lowered to a height above the canopy to achieve maximum insertion of nylon rods into the fruiting canopy. A crew of five sorted and packed the fruit. The shaking unit easily moved through theslanted fruit canopy. $\mathrm{H}$ ow- 
Fig. 6. Schematic of USD A fresh blackberry harvester.

ever, some breakage of fruiting laterals and excessive removal of immature fruit occurred during the initial two harvests. Between $40 \%$ and $70 \%$ of the machine-harvested fruit was in the fresh-market category and the rest was in the overripe, bruised, leaky, or immature categories. An economic evaluation of machine harvesting blackberries for fresh market indicted that the rotatable cross arm trellis system would need a packout of $71 \%$ to equal the fresh market return of aconventional I trellis system that is hand harvested ( $\mathrm{H}$ arper et al., 1998).

\section{Conclusions}

The ultimate goal of machine harvesting eastern thornless blackberries with a high percentage of fruit with fresh-market quality now appears attainable. Wenow havedeveloped ablackberry harvester that can remove $90 \%$ of the ripe fruit without removing immature fruit. $\mathrm{N}$ ew trellis designs and canetraining procedureshave contributed to high machine harvestability of semierect blackberry. These improvements in the management of blackberry plants have increased the quality of machine harvested fruit and reduced theworkneeded to train and tie primocanes without sacrificing blackberry productivity.

A new over-the-row, singlespiked-drum shaker, which can effectively detach ripe fruit from a horizontally oriented canopy, was developed. Its size and maneuverability are similar to conventional shakers designed for harvesting vertically oriented canopies. Its moving fruit-catching surface positioned just underneath thefruiting clusters will reduce fruit bruising and damage. In the next several years, additional field work will be done to evaluatedifferent shaker oscillating frequencies and stroking span to improve fruit removal and quality. After the harvester has been developed further and canopy management strategies refined, the best way to mechanically harvest blackberries will be determined.

\section{Literature cited}

Booster, D.E. 1983. Berry harvesting: I II. Cane and high bush berry harvesting, p. 519-523. In: M. O'Brien, B.F. Cargill, and R.B. Fridley (eds.). Principles and practices for harvesting and handling fruits and nuts. AVI Publishing Co., Westport, Conn.

Brown, G.K., D.E. M arshall, B.R.T ennes, D.E. Booster, P. Chen, R.E. Garrett, M. O'Brien, H.E. Studer, R.A. Kepner, S.L. H edden, E.E. H ood, D.H. Lenker, W.F. M illier, G.E. Rehkugler, D.L. Peterson, and L.N . Shaw. 1983. Status of harvest mechanization of horticultural crops. Amer. Soc. Agr. Eng. (St. J oseph, M ich.) Paper 83-3.

D unn, J.S, M. Stolp, and G.G. Lindsay. 1976. $M$ echanical raspberry harvesting and the Lincoln canopy system. Amer. Soc. Agr. Eng. (St. J oseph, M ich.) Paper 76-1543.

$\mathrm{H}$ alat, M.S., C.A. Reitmeier, F. Takeda, and D.L. Peterson. 1997. Sensory evaluation of jams made from three eastern thornless and M arion blackberries. J. Food Qual. 20:177188.

H arper, J.K., F. Takeda, and D.L. Peterson. 1998. Economic evaluation of improved mechanical harvesting systems for eastern thornlessblackberries. D ept. Agr. E con. Rural Sociol., Pa. State U niv., U niversity Park, Staff Paper 321.

Kingston, C.M. 1991. Defining fruit losses in machine-harvested raspberries. N.Z. J. Crop H ort. Sci. 19:275-281.

M artin, L.W. and F.J. L awrence. 1976. A synopsis of mechanical harvesting of $R$ ubus in O regon. Acta H ort. 60:95-98.

Moore, J.N. and R.M. Skirvin. 1990. Blackberrymanagement, p. 214-244. In: G.J. Galletta and D.G. H imelrick (eds.). Small fruit crop management. Prentice $\mathrm{H}$ all, Englewood Cliffs, N.J.

Morris, J.R., G.S. N elson, A.A. Kattan, and D.L. Cawthon. 1978. D eveloping a mechanical harvesting and production system for erect blackberries. H ortScience 13:228-235.

O ydvin, J. 1986. The Gjerde method for training raspberries. Effects of increasing cane number and cane height. Acta H ort. 183:173-181.

Peterson, D.L., F. Takeda, and T. Kornecki. 1989. N ew shaking conceptsfor brambles. T rans. Amer. Soc. Agr. Eng. 32:1165-1168.

Peterson, D.L., F. Takeda, and T. Kornecki. 1992. $\mathrm{H}$ arvester for " $T$ ", " $V$ ", and " $Y$ " trellised eastern thornless blackberries. Appl. Eng. Agr. 8:9-12.

Steiner, P.W., C.S. Walsh, and E.R. Krestensen. 1983. M aryland commercial small fruit recommendations. M d. Coop. Ext. Bul. 242.

Stiles, H .D . 1995. Shift-trellises for better management of brambles (R ubus cvs.). Va. Agr. Expt. Sta. (Blacksburg) Bul. Ser. 95-2.

Takeda, F. and D.L. Peterson. 1996. M echanical harvester, trellis designs and canetraining for eastern thornless blackberry production. Proc. 1996 Annu. Conf. N. Amer. Bramble Growers Assn., Cumberland, M d.

Takeda, F., D .L. Peterson, J.D . Franklin, and T. Kornecki. 1989. M achine harvesting system for eastern thornless blackberries. Acta Hort. 262:411-419.

Warmund, M.R., F. Takeda, and G.A. D avis. 1992. Supercooling and extracellular ice formation in differentiating buds of eastern thornless blackberry. J. Amer. Soc. H ort. Sci. 117:941945. 